B. С. Тарханова, Н. А. Шинкарева. Анализ организационно-педагогических условий для развития выразительности движений в танцевальной деятельности у детей старшего дошкольного возраста

Научная статья

УДК 373.2

DOI: $10.18101 / 2307-3330-2021-4-83-86$

\title{
АНАЛИЗ ОРГАНИЗАЦИОННО-ПЕДАГОГИЧЕСКИХ УСЛОВИЙ ДЛЯ РАЗВИТИЯ ВЫРАЗИТЕЛЬНОСТИ ДВИЖЕНИЙ В ТАНЦЕВАЛЬНОЙ ДЕЯТЕЛЬНОСТИ У ДЕТЕЙ СТАРШЕГО ДОШКОЛЬНОГО ВОЗРАСТА
}

\author{
(C) Тарханова Виктория Сергеевна \\ студентка, \\ Иркутский государственный университет \\ Россия, 664003, г. Иркутск, ул. Карла Маркса, 1 \\ vika17042015@mail.ru \\ (C) Шинкарева Надежда Алексеевна \\ кандидат педагогических наук, доцент, \\ Иркутский государственный университет \\ Россия, 664003, г. Иркутск, ул. Карла Маркса, 1 \\ Iren433@mail.ru
}

\begin{abstract}
Аннотация. В статье рассматриваются организационно-педагогические условия развития выразительности движений у детей старшего дошкольного возраста в танцевальной деятельности (повышение осведомленности и интереса родителей к развитию координации движений у детей дошкольного возраста; повышение компетентности педагогов в области организации работы по развитию выразительности движений у детей дошкольного возраста в танцевальной деятельности; пополнение развивающей предметно-пространственной среды, способствующей развитию выразительности движений у старших дошкольников в танцевальной деятельности; пантомимы; сценки), отражены взгляды различных авторов и проанализированы условия эффективной организации работы по трем направлениям: педагоги, среда, родители. Рассмотрены следующие формы работы с родителями: индивидуальные, групповые и массовые. В результате экспериментального исследования разработан порядок построения занятия по развитию выразительности движения.

Ключевые слова: образовательный процесс, «педагогические условия», развитие выразительности движений в танцевальной деятельности, развивающая предметнопространственная среда, форма работы с родителями.
\end{abstract}

\section{Для цитирования}

Тарханова В. С., Шинкарева Н. А. Анализ организационно-педагогических условий для развития выразительности движений в танцевальной деятельности у детей старшего дошкольного возраста // Вестник Бурятского государственного университета. Образование. Личность. Общество. 2021. № 4. С. 83-86.

Для эффективного развития выразительности движений в танцевальной деятельности важно создать необходимые условия. В организации образовательного процесса важно делать акцент не только на организацию пространства, а также важно обращать внимание и на и содержание формы работы, и процесс взаимодействия педагога с детьми и их родителями. 
В. И. Андреев, изучая особенности организации образовательного процесса, понятие «педагогические условия» трактует как: «комплекс мер, содержание, методы, приемы и организационные формы обучения и воспитания» [1, с. 38].

Организация работы по развитию выразительности движений в танцевальной деятельности детей старшего дошкольного возраста будет строиться на основе соблюдения необходимых организационно-педагогических условий, который выделил Е. Ф. Бехтенова:

1) Повышение осведомленности и интереса родителей по вопросу развития выразительности движений у детей шестого года жизни.

2) Повышение компетентности педагогов в области организации работы по развитию выразительности движений в танцевальной деятельности у детей шестого года жизни.

3) Наполнение развивающей предметно-пространственной среды, способствующей развитию выразительности движений в танцевальной деятельности у детей шестого года жизни [2, с. 175].

Рассматривая первое условие, стоит отметить, что семья это самый первый и важный социальный институт общества для ребенка, поэтому необходимо организовывать нужную помощь родителям по вопросам развития, воспитания и обучения ребенка.

В своих исследованиях А. А. Гуз выделяет следующие формы работы с родителями: индивидуальные, групповые и массовые.

К индивидуальной работе с родителями автор относит такие формы работы как: личные беседы, родительские консультации, педагогические поручения для родителей и посещение семьи воспитанника (по необходимым мерам). К групповой работе с родителями чаще всего относят выбранный родительский комитет. К массовой работе с родителями относят следующие формы: педагогические лекции, круглый стол по заданной теме, конференции и родительское собрание [3, с. 105].

Второе условие, которое предполагает повышение компетентности педагогов в области организации работы по развитию выразительности движений, выделяет следующие особенности.

С. Н. Мухина полагает, что именно в специально подобранных играх, упражнениях и музыкальных сопровождениях дети перевоплощаются пластически в определенный игровой образ. Следовательно, с помощью осмысленного перевоплощения в игровой образ у дошкольников развивается способность отделять собственные действия и эмоции от образных выражений и переживаний. Это происходит в результате того, что у детей развивается возможность управлять своими эмоциями и движениями [5, с. 34].

Во время занятий Е. В. Горшкова утверждает, что педагогу важно верно подбирать формулировку содержания задания для дошкольников. Нужно подбирать такие слова, которые не будут в дальнейшем подсказкой для выполнения задания, конкретных движений, мимики, жестов и так далее. Важно дать возможность ребенку проявить творчество и уникальность в выполнении заданий на выразительность движений.

А также, Е. В. Горшкова отмечает важность использования материалов на занятиях, которые включают в себя отдельные жесты, способы выражения пере- 
B. С. Тарханова, Н. А. Шинкарева. Анализ организационно-педагогических условий для развития выразительности движений в танцевальной деятельности у детей старшего дошкольного возраста

живаний и отношений. Автор акцентирует внимание на том, что данные материалы должны использоваться и закрепляться в повседневной жизни ребенка, а именно, в играх, в общении со сверстниками и с взрослыми, и в других видах деятельности.

Анализируя теорию Е. В. Горшковой, мы рассмотрели порядок построения занятия по развитию выразительности движения. В начале занятия важным является разминка, где проходит подготовка мышц и включение тела в активное движение.

Далее, переходя к основной части занятия, производиться знакомство с особенностями выразительных движений, способами их использования в том или ином образе. А также в основной части занятия детям следует разыграть ситуацию, в котором будет присутствовать эмоциональное практическое взаимодействие с партнером. Здесь же происходит выполнение различных выразительных движений под соответствующее музыкальное сопровождение.

В заключительной части занятия, детям предлагают разыграть этюд или пантомиму с использованием тех выразительных движений, которые рассматривались на занятии. Также важно в конце занятия подводить итог, то есть проводить с детьми рефлексию, где дети могут поделиться своими впечатлениями и рассказать о умениях, которые приобрели на занятии или наоборот, рассказать о возможных неудачах исполнения движений [4, с. 13].

Третье организационно-педагогическое условие, направленное на наполняемость предметно-пространственной среды, также является немаловажным в развитии выразительности движений старших дошкольников.

В танцевальной деятельности музыкальное сопровождение занимает важную ступень. С. Н. Мухина отмечает, что музыка выступает в качестве вспомогательного средства и необходима для создания определенной атмосферы настроения. Также музыка помогает в поиске выразительных движений, способствует установке соответствий пластического образа характеру музыки [5, с. 65].

А также к организации пространства стоит отнести оборудования необходимые для педагогического процесса (музыкальные инструменты, магнитофон, микрофон), музыкально-танцевальный зал, костюмы, используемые в музыкальных играх, пантомимах, этюда, сценках и в самих танцах для передачи образа исполняемого персонажа, и образные предметы, картинки для демонстрации.

Исходя из выше сказанного, стоит сделать вывод того, что в своей исследовательской работе по данной тематике, мы будем использовать следующие организационно-педагогические условия: повышение осведомленности и интереса родителей по вопросу развития координации движений у детей дошкольного возраста; повышение компетентности педагогов в области организации работы по развитию выразительности движений у детей дошкольного возраста в танцевальной деятельности; пополнение развивающей предметно-пространственной среды, способствующей развитию выразительности движений у старших дошкольников в танцевальной деятельности; пантомимы; сценки.

\section{Литература}

1. Андреев В. И. Диалектика воспитания и самовоспитания творческой личности. Казань: Изд-во КГУ, 1988. 238 с. Текст: непосредственный. 
2. Бехтенова Е. Ф. Педагогические условия формирования проектной деятельности учащихся. Новосибирск, 2006. 23 с. Текст: непосредственный.

3. Гуз А. А. Взаимодействие дошкольного учреждения и семьи: пособие для педагогов учреждений, обеспечивающих получение дошк. образования. Мозырь, 2007. 235 с. Текст: непосредственный.

4. Горшкова Е. В. О развитии образно-пластического творчества у дошкольников: вопросы теории и практики. URL: https://cyberleninka.ru/article/n/orazvitii obrazno plasticheskogo-tvorchestva-u-doshkolnikov-voprosy-teorii-i-praktiki.Загл. с экрана (дата обращения: 27.12.2021). Текст: электронный.

5. Мухина С. Н. Способы развития выразительности движений у старших дошкольников в специально организованной деятельности. Москва: Сфера, 2009. 168 с. Текст: непосредственный.

Статья поступила в редакицю 02.10.2021; одобрена после рецеенирования 13.10.2021; принята к публикачии 15.12.2021.

\title{
THE ANALYSIS OF ORGANIZATIONAL AND PEDAGOGICAL CONDITIONS FOR THE EXPRESSIVE MOVEMENTS DEVELOPMENT IN SENIOR PRESCHOOL CHILDREN'S DANCE ACTIVITIES
}

\author{
Victoria S. Tarkhanova \\ Student \\ Irkutsk State University \\ 1 Karl Marx St., Irkutsk, 664003, Russia \\ vika17042015@mail.ru \\ Nadezhda A. Shinkareva \\ Candidate of Pedagogical Sciences, Associate Professor \\ Irkutsk State University \\ 1 Karl Marx St., Iirkutsk, 664003, Russia \\ Iren433@mail.ru
}

The article discusses the features of organizing organizational and pedagogical conditions for movements expressiveness development in senior preschool children's dance activities (raising awareness and interest of parents to the development of coordination of movements of preschool children; increasing the competence of teachers in the field of work on the development of movements expressiveness development in senior preschool children's dance activities; replenishment of the developing subject-spatial environment that promotes the development of expressiveness of movements from senior preschoolers in dance activities; pantomimes; scenes), the views of various authors are presented and the conditions for the effective organization of work on three areas are considered: teachers, environment, parents. The following forms of work with parents are considered by the authors: individual, group and mass. As a result of the experimental study, the procedure for building movement expressiveness development class was developed.

Keywords: educational process, «pedagogical conditions», movements expressiveness development in dance activities, developing a subject-spatial environment, a form of work with parents.

The article was submitted 02.10.2021; approved after reviewing 13.10.2021; accepted for publication 15.12.2021. 